\title{
Ground-to-Space Monitoring of Anthropogenic Impacts on the Coastal Zone of the Crimean Peninsula
}

\author{
V. G. Bondurl, V.A.Ivanov ${ }^{2}$, V. E. Vorobiev', V.A. Dulov ${ }^{2, *}$, \\ V. V. Dolotov', V. V.Zamshin', S. I. Kondratiev', M. E. Lee ${ }^{2}$, \\ V. V. Malinovsky ${ }^{2}$ \\ ${ }^{1}$ AEROCOSMOS Research Institute for Aerospace Monitoring, \\ Moscow, Russian Federation \\ ${ }^{2}$ Marine Hydrophysical Institute of RAS, Sevastopol, Russian Federation \\ *dulov1952@gmail.com
}

\begin{abstract}
Purpose. The aim of the work is to develop, construct and test the experimental model for the groundto-space monitoring of anthropogenic impacts on the Crimean coast using satellite and surface data. The system is intended to obtain significant parameters of marine environment required for revealing the anthropogenic impact sources, developing feasible recommendations on sustainable nature management and decreasing the anthropogenic load on marine ecosystems.

Methods and Results. The paper represents description of the monitoring structure and the equipment focused on the ground segment of the system applied in the Marine Hydrophysical Institute of RAS, as well as the example of its implementation in monitoring the Crimean coastal water areas. Discussed is the concept of the ground-to-space monitoring of anthropogenic impacts on the coastal water areas which constitutes a foundation of the proposed system. The ground sub-satellite segment of the monitoring system intended for collecting, processing and storing the information obtained from the contact sensors is described. Special attention is paid to the workstation permitting to perform operational analysis of the obtained data. The experience of successful application of the monitoring system is represented. Arrangement of the field studies is described. Main results obtained from testing the monitoring system are briefly reviewed. Comprehensive analysis of subsatellite data and multi-spectral satellite images is shown by the example of detecting the emergency break at the main wastewater line in Sevastopol.

Conclusions. The system of ground-to-space monitoring of the anthropogenic impacts on the Crimea coastal zone was developed, implemented and tested. The system functioning in 2015-2016 demonstrated its high efficiency in operational and complex analysis of direct and satellite data, especially in revealing emergency situations related to wastewater discharges to the sea.
\end{abstract}

Keywords: remote sensing of Earth, ground-to-space monitoring, coastal water areas, anthropogenic impact, subsurface processes, in situ measurements, geo-information systems.

Acknowledgments: the work is carried out within the framework both of the State tasks No. 08272019-004 (MHI) and No. 0588-2019-0030 (ISR “AEROCOSMOS”) at financial support of Ministry of Education and Science and the project No. RFMEFI60419X0223.

For citation: Bondur, V.G., Ivanov, V.A., Vorobiev, V.E., Dulov, V.A., Dolotov, V.V., Zamshin, V.V., Kondratiev, S.I., Lee, M.E. and Malinovsky, V.V., 2020. Ground-to-Space Monitoring of Anthropogenic Impacts on the Coastal Zone of the Crimean Peninsula. Physical Oceanography, [e-journal] 27(1), pp. 95-107. doi:10.22449/1573-160X-2020-1-95-107

DOI: 10.22449/1573-160X-2020-1-95-107

(C) V.G. Bondur, V.A. Ivanov, V.E. Vorobiev, V.A. Dulov, V.V. Dolotov, V.V. Zamshin,

S.I. Kondratiev, M.E. Lee, V.V. Malinovsky, 2020

(C) Physical Oceanography, 2020 


\section{Introduction}

The ecological state of the Black Sea remains problematic. This is due to the anthropogenic load increase, primarily in the coastal areas of the Black Sea, as well as to an increased risk of technological accidents and natural disasters $[1,2]$. Moreover, there are practically no regular comprehensive studies of the state of coastal areas and separate bays, although it is there that emergency and extremely unfavorable situations associated with anthropogenic impacts can be expected $[1,3]$. Under these conditions, it is vital to develop systems for monitoring the state of the marine environment and ecosystems in coastal zones [4-7].

Monitoring of the coastal water areas state is traditionally carried out by ground-based (see, for example, [8-11]) or space (see, for example, [6, 7, 9, 12-17]) means.

Ground monitoring is based on continuous or fragmented contact information at specific points in the water, sometimes at coastal stations. By now, large databases of in situ measurements have been accumulated for the coastal areas of the Black, Barents and Kara Seas (see, for example, [18]). A significant drawback of ground monitoring is the inability to cover the entire area of interest, for example, shelf zones of the Black Sea coast of the Russian Federation. In addition, contact measurements in marine conditions are an expensive part of this method, since they require the involvement of expensive measuring equipment and carriers (vessels platforms, etc.), as well as highly qualified specialists for carrying out measurements and their analysis [8, 10-12, 19].

In turn, space monitoring based on the analysis of satellite images of coastal waters cannot provide all the necessary information with the required detail $[2,12-16]$.

For adequate estimation of the important characteristics of the aquatic environment, remote data require calibration and validation using sub-satellite information [9-11, 19], leading to the need to combine the results of remote and contact measurements. Such integration is also necessary for model calculations for the purpose of diagnosing or predicting processes in the marine environment under anthropogenic impact $[12,15]$.

Integrated monitoring of the marine environment based on satellite and ground measurements was successfully applied in a number of separate studies (see, for example, $[11,15,18])$. However, its systematic application using a special system of interacting satellite and ground segments remains at the stage of discussion of the future plans [19].

In 2015-2016 an experimental model of a system of ground-to-space monitoring of anthropogenic impacts on the coastal zone of the Crimean Peninsula was developed, created and tested. This article highlights the successful experience of organizing and carrying out of this work, presents a conceptual and technical description of the system, its structure and features with an emphasis on its ground segment, implemented on the basis of Marine Hydrophysical Institute. The functioning of the system is considered on the example of a comprehensive analysis of sub-satellite data and multispectral satellite imagery, as a result of which an emergency break of the main sewage discharge line in Sevastopol was found. 


\section{Coastal water area monitoring concept}

The concept of ground-to-space monitoring of coastal waters is as follows:

1. As a result of the collection and accumulation of synchronous and quasisynchronous contact and satellite data, ideas about the background (safe) state of the considered water areas and its anomalous changes associated with anthropogenic impacts and, possibly, with natural factors are formed.

2. Anomalies detected during satellite monitoring are promptly studied by contact means. Studies, in particular, include determining the characteristics of the marine environment that cannot be obtained from satellite measurements. The processing satellite data methods are being tuned and the results of their processing are validated $[14,15,20]$.

3. Adequate assessments of the ecological state of water areas and levels of negative impacts on them are formed.

4. In case of environmental disruption or threat of a disaster, recommendations on environmental management are given and relevant information is provided to interested state and regional structures $[14,15]$.

Within the framework of the presented concept, taking into account the results of previous studies [14, 15, 21-23], an experimental model of a monitoring system for anthropogenic impacts on the shelf zones of the Black Sea coast of the Russian Federation (hereinafter referred to as the Monitoring System) was created, using satellite and contact data. The space segment of the system was considered in detail in [24], a number of results obtained during its testing are given in $[2,25,26]$. This paper presents the sub-satellite segment of the Monitoring System, which provides the collection, processing and storage of the sub-satellite data.

\section{The structure and composition of the sub-satellite segment of the ground-to-space Monitoring System}

Composition of basic elements considered segment of the Monitoring System shown in Fig. 1.

Contact data on anthropogenic impacts on coastal waters are obtained, as a rule, from vessels, coastal stations and offshore platforms and drifting buoy stations [8-10, 14]. R/V Biryuza, the stationary oceanographic platform (SOP) and the coastal instrument complex of Marine Hydrophysical Polygon of RAS in Katsiveli village, a complex of flow hydrophysical associated measurements, in which the measurement process and data structure correspond to the buoy stations, were involved in the testing of the functioning of the experimental sample of the Monitoring System for collecting satellite data.

Measuring instruments were selected taking into account the requirements for measuring the background characteristics of water, identifying anthropogenic and natural pollution sources and validating the processing space data results. Subsatellite measurements cover:

- characteristics of the sea surface and the atmosphere driving layer necessary for the satellite data interpretation;

- hydrological characteristics of waters, including vertical profiles of temperature and salinity, current velocity vector and records of internal waves;

- turbulence characteristics; 
- optical characteristics of the water column and sea surface;

- hydrochemical and microbiological characteristics of water.

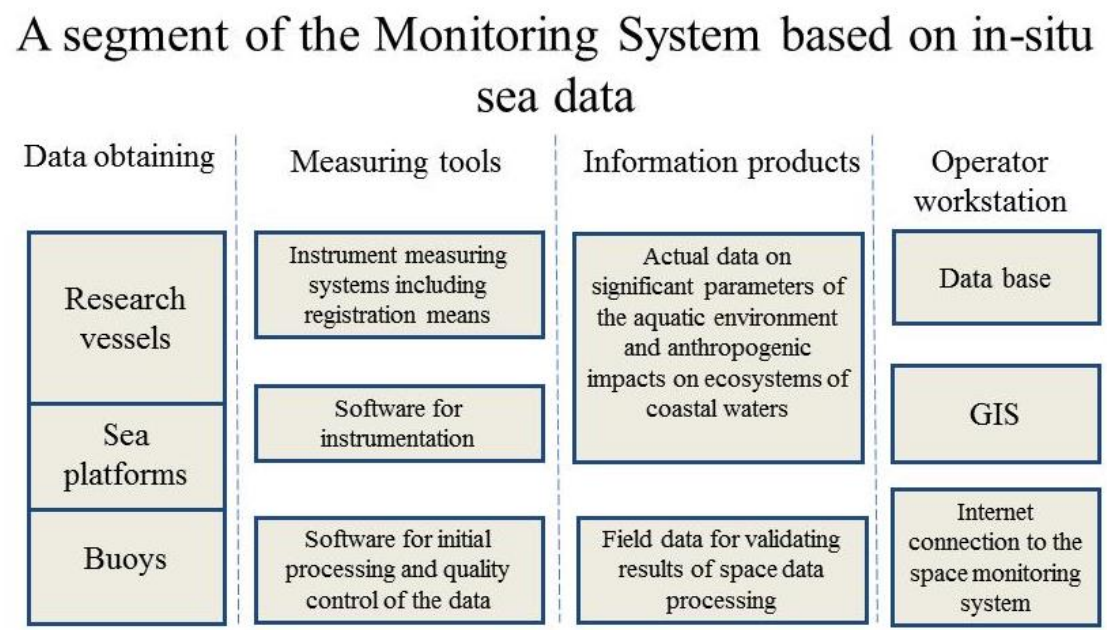

F i g. 1. Structural scheme of sub-satellite segment of the ground-to-space Monitoring System

For the sub-satellite data processing, software related to instrumentation complexes and special programs for the primary processing and quality control of each data type was applied.

Information products, which represented data files with a fixed structure, contained relevant field information on significant parameters of the aquatic environment and anthropogenic impacts on coastal ecosystems, as well as contact information recorded at the time of satellite imagery. This allowed the validation of space data processing results. Information products have significantly simplified the transition from field measurements to the analysis of their results [10].

When testing the functioning of the experimental model of the Monitoring System, the subsatellite segment formed 22 types of information products, including the following ones:

- general meteorological characteristics,

- frequency-angle spectra of surface waves,

- hydrological structure of waters,

- currents (ADCP data),

- vertical light attenuation profiles,

- distribution of hydrochemical characteristics,

- distribution of hydrobiological characteristics,

- related data on the hydrometeorological situation (synoptic maps, driving wind maps based on open scatterometer data, model calculations), etc.

Within each information product, the data was distributed according to specific types of significant parameters of the aquatic environment, for example, 
hydrochemical characteristics included: oxygen content, water saturation with oxygen (in \%), total inorganic carbon content, alkalinity, phosphate content, silicic acid content, nitrate and nitrite content, content ammonium ions, total suspension and acidity.

The System operator's workplace is intended for the operational analysis of full-scale oceanographic data, as well as for the automatic assimilation of archival and relevant information on monitoring coastal waters. It provides the exchange of information with the Monitoring System via the Internet [24]. The workplace combines a database (DB) and a geographic information system (GIS) of oceanographic orientation. The database is formed from relevant, archival and related information, which could be supplemented by photos and videos from the research area, satellite data and simulation results [27]. Using the database allowed:

- include any number of bitmaps;

- visualize all materials in any combination against the background of a base map with up to 10 thematic layers (including land and sea topography);

- organize named spatial bookmarks with the aim of quick spatial movement on the map;

- obtain vertical distributions of any measured parameters at the selected oceanographic station;

- process trace and time records;

- carry out horizontal spatial interpolation for any horizon or selected water layer with the generation of a digital array in the GS Surfer7 Binary GRID format, presenting the results in the form of grid regular distributions, followed by the implementation of geoprocessing functions;

- display an image of the working window with all tabs in the JPG-format or web-page;

- export spatially referenced raster images in GeoTIFF-format.

Examples of using these features are illustrated in Fig. 2 where the operator's working window is shown. In order to perform hydrological analysis, we can display the selected area with the position of the stations in a given period of time, select a station and consider hydrological profiles (Fig. 2, a). The data on the surface layer turbidity in the area of water treatment facilities in Simeiz on 05.28.2016 include both a map of the vessel's route and a record along the route (Fig. 2, b). The satellite image can be combined with a contour map of the sea surface temperature obtained from the contact measurements (Fig. 2,c). An analysis of the sea surface state can be performed based on the measured frequency-angular spectra of surface waves (Fig. 2, $d$, white line gives the wind direction). 

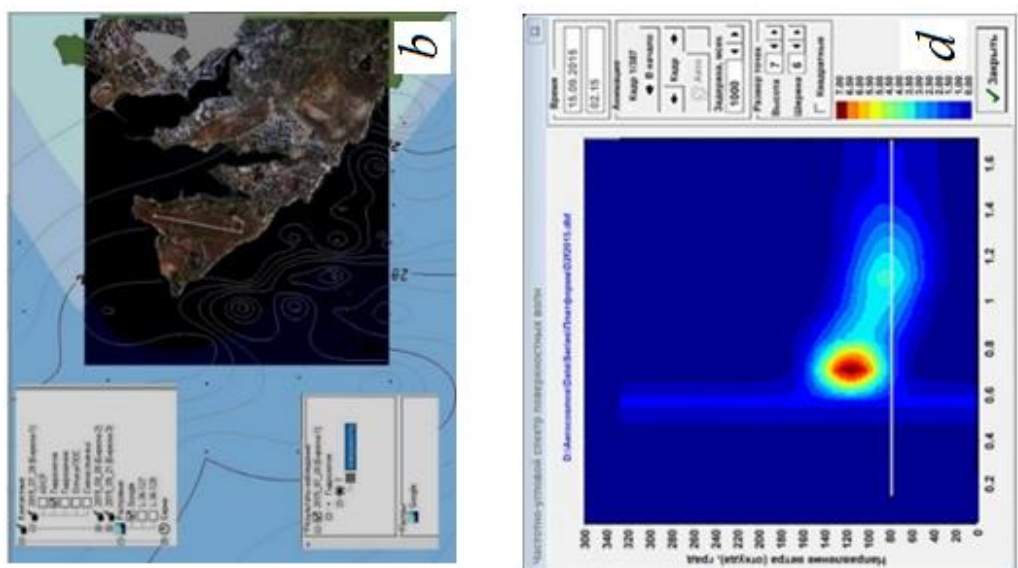

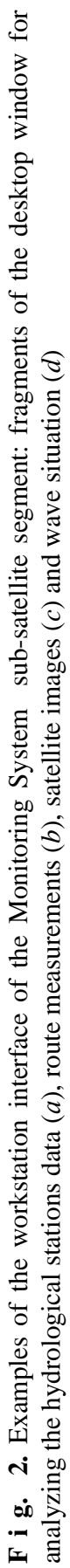
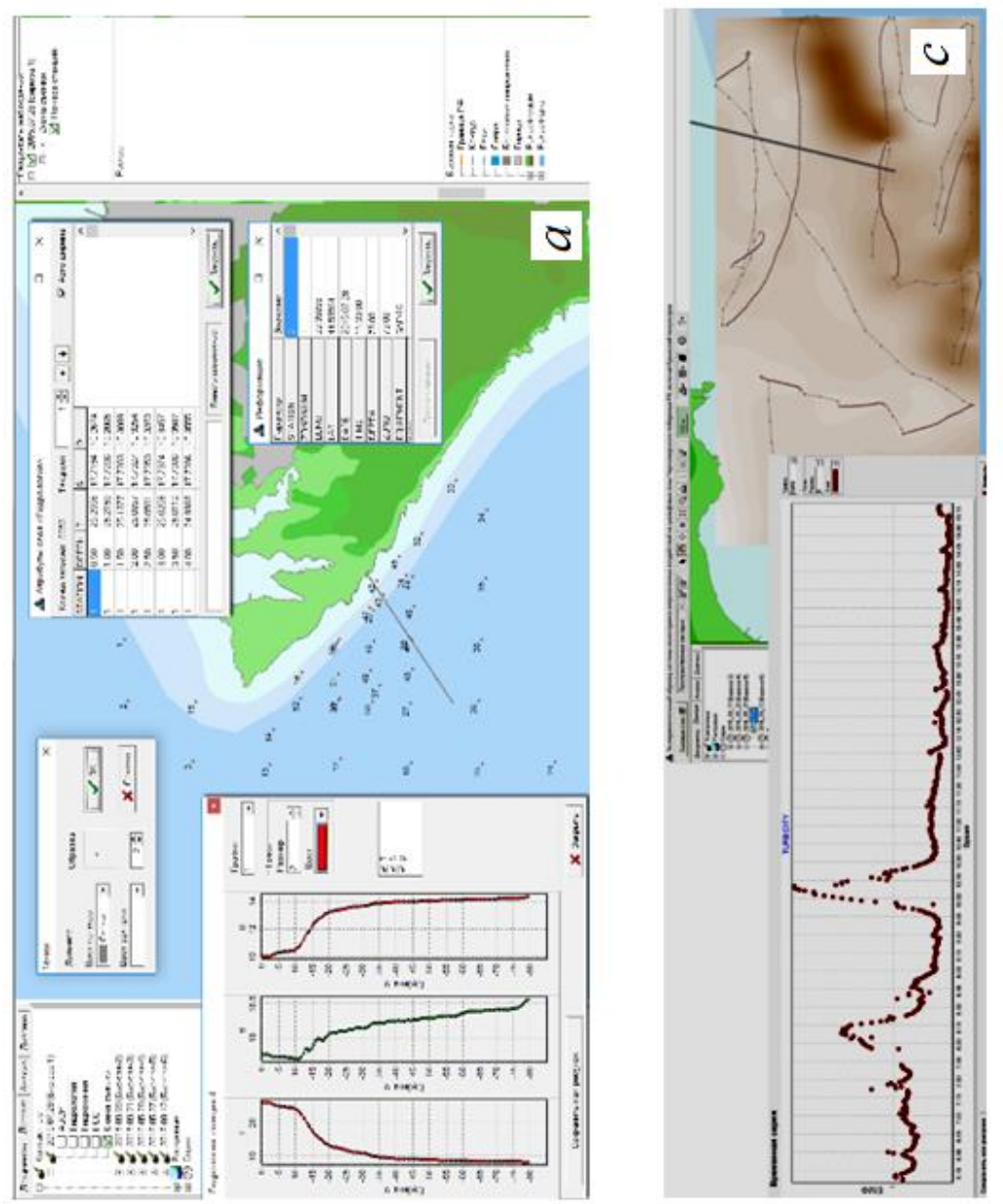


\section{Some results of experimental studies and their analysis}

In order to adjust the functions of the Monitoring System sub-satellite segment, during the testing of the experimental prototype of this system a series of expeditions to the areas characterized by intense anthropogenic impacts associated with deep sewers, including eight expeditions to the Crimean Peninsula shelf (table), were carried out. At the same time, satellite survey was performed from various satellites.

\section{Expeditions at the Crimean Peninsular shelf}

\begin{tabular}{l|c|c|c}
\hline Name of expedition & Name of test polygon & Polygon coordinates & Period of expedition \\
\hline \multicolumn{4}{l}{$\begin{array}{l} \\
\text { The } 1^{\text {st }} \text { cruise of R/V }\end{array}$} \\
"Biryuza" & Test polygon near the & $44.490^{\circ}-44.590^{\circ} \mathrm{N}$, & July 28-31, 2015 \\
& Heraclean Peninsular & $33.310^{\circ}-33.430^{\circ} \mathrm{E}$ &
\end{tabular}

The $2^{\text {nd }}$ cruise of R/V Test polygon near the "Biryuza" $44.490^{\circ}-44.590^{\circ} \mathrm{N}$ $33.310^{\circ}-33.430^{\circ} \mathrm{E}$

September 9-10, 2015

Test polygon in the region of stationary oceanographic platform in Katsiveli $44.388^{\circ}-44.398^{\circ} \mathrm{N}$, $33.980^{\circ}-33.992^{\circ} \mathrm{E}$

The $3^{\text {rd }}$ cruis
"Biryuza"
September 20-22, 2015

$44.388^{\circ}-44.398^{\circ} \mathrm{N}$, $33.980^{\circ}-33.992^{\circ} \mathrm{E}$

September 15-25, 2015 platform

The $4^{\text {th }}$ cruise of R/V Test polygon near the "Biryuza" Heraclean Peninsular

The $5^{\text {th }}$ cruise of $\mathrm{R} / \mathrm{V}$ "Biryuza"

Test polygon near Simeiz

The $6^{\text {th }}$ cruise of $\mathrm{R} / \mathrm{V}$ "Biryuza"

Test polygon near the Heraclean Peninsular

Test polygon in the

Work at stationary oceanographic platform region of stationary oceanographic platform in Katsiveli $44.490^{\circ}-44.590^{\circ} \mathrm{N}$ $33.310^{\circ}-33.430^{\circ} \mathrm{E}$

$44.380^{\circ}-44.400^{\circ} \mathrm{N}$ $33.995^{\circ}-34.033^{\circ} \mathrm{E}$

$44.490^{\circ}-44.590^{\circ} \mathrm{N}$, $33.310^{\circ}-33.430^{\circ} \mathrm{E}$

September 12-13, 2016

$44.388^{\circ}-44.398^{\circ} \mathrm{N}$, $33.980^{\circ}-33.992^{\circ} \mathrm{E}$
September 14-30, 2016 
During the expedition a wide range of optical characteristics of water and small-scale characteristics of the sea surface were recorded using different instruments and original techniques, such as:

- measuring instrument of spectral-angular indicator of light scattering and the sea water fluorescence,

- universal spectrophotometer for measuring the sea brightness coefficients,

- spectral measuring instrument of light attenuation indicator,

- spectral measuring instrument of underwater irradiation vertical profile,

- solar photometer for measuring the spectral optical thickness of the atmosphere,

- stereo system for evaluating the spectra of short sea waves,

- laser locator for studying the sea surface curvature,

- video recorder for detecting wave breaking, etc. (for a description of devices and methods, see, for example, [8]).

The work was carried out synchronously and quasi-synchronously with the survey of the area from Resurs-P 1/2, GeoEye, Landsat-7/8, Sentinel-1/2 [24] satellites.

The successful validation of the technique for reconstructing wave spectra from the spectra of high-resolution satellite images should be noted [25] as one of the results of experimental studies. Another important result is the identification of an emergency situation in the area of the main sewage discharge in Sevastopol. In the process of testing the functions of the Monitoring System space segment, optical anomalies were discovered on satellite images that could naturally be associated with a wastewater plume [2, 24, 28]. Within the framework of ship expeditions, a large amount of field data on the physical and biochemical characteristics of this plume, reliably showing that it is associated with the rise of wastewater to the sea surface due to the break of the sewage line [26], was obtained. Thus, reliable validation of the results of determination of the aquatic environment optical anomalies from satellite images due to the inflow of deep drains into the coastal waters from emergency breaks of collectors of dumping devices was performed [2, 24].

In Fig. 3 an example of a comprehensive analysis of the results of processing the sub-satellite data and multispectral space images obtained for a testing site in the area of the Heracles Peninsula (near Sevastopol) is given. In this example, for the remote detection of anomalies in the hydro-optical characteristics of the aquatic environment caused by the deep sewage water inflow into the aquatic environment, we used the spatial distributions of the color index values obtained as a result of specialized processing of high-resolution multispectral space images [2, 12, 13, 24].

In Fig. 3, $a$ the fragments of time series of processed satellite images obtained on February 18, May 10 and 25, July 8 and September 10, 2015 from GeoEye-1 and WorldView-2, 3 satellites are given. Fig. 3, $b$ represents an enlarged fragment of the processed image obtained on May 10, 2015 from the WorldView-3 satellite. An optical anomaly, adjoining from the southeast to the collector location line (in the area of the emergency break), is clearly visible on the fragment. 

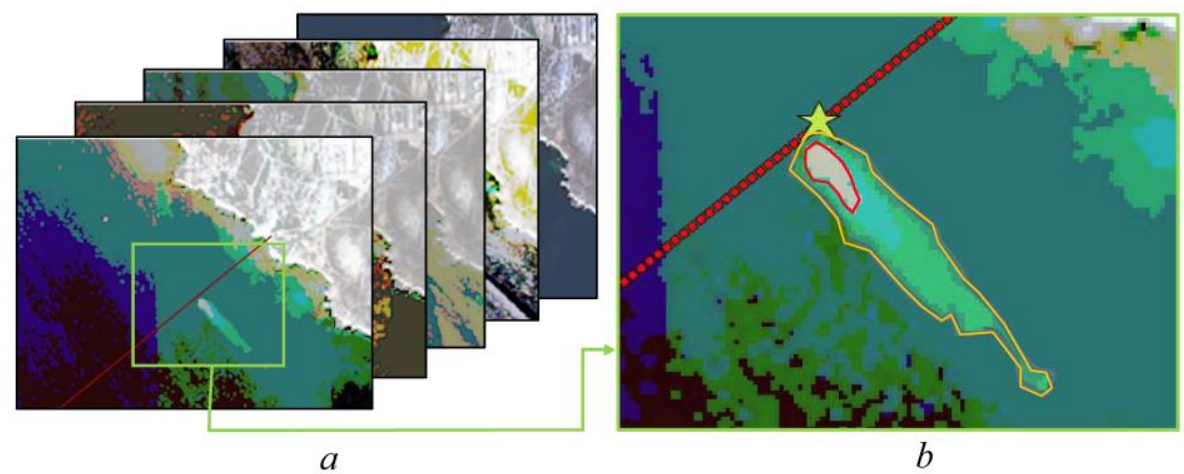

b

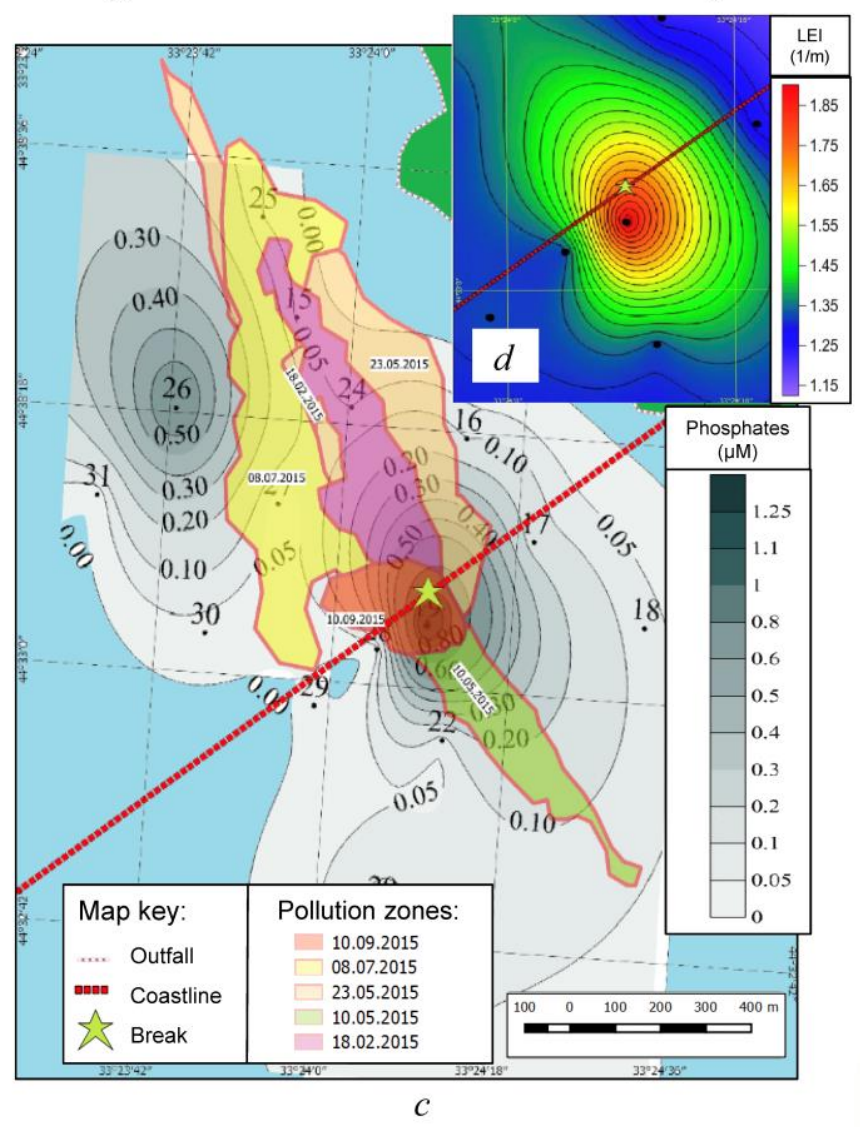

F i g. 3. Examples of processing space optical multi-spectral images: $a$ - initial set of satellite images; $b$ - fragment of the image for 10.05.2015; $c$ - satellite derived optical anomalies imposed on the phosphate distribution; $d$-data of contact hydrooptical measurements

In Fig. 3, $c$ a generalized map of anomalies (recorded in the experiments carried out in 2015) caused by the propagation of deepwater discharges from the wastewater line break is given. This figure also shows the distribution of phosphate content measured by contact sensors at depths from 0 to $5 \mathrm{~m}$ (increased phosphate content is observed in the area of the discharge device collector rupture). In Fig. 3, $d$ the results of sub-satellite ship measurements of light attenuation at 
a wavelength of $370 \mathrm{~nm}$, in the distribution field of which there is also a sharp anomaly in the region of the emergency rupture, are presented. An analysis of Fig. 3, $c$ shows that the detected rupture of the discharge device collector (symbolically marked with an asterisk) is located at about $800 \mathrm{~m}$ distance from the coast, while the discharge device has a total length of $3.3 \mathrm{~km}$. It must be therefore concluded that the emergency break of the main wastewater line takes place.

\section{Conclusion}

Based on the concept of ground-to-space monitoring of coastal waters, a ground-space system sub-satellite segment for monitoring the anthropogenic impacts on the offshore areas of the Black Sea coast of the Russian Federation was created. This provides the collection, processing and storage of information received from contact sensors. In order to refine the functions of the monitoring system sub-satellite segment, a number of field studies were performed. During them, simultaneously with satellite imagery, the distributions of significant parameters of the aquatic environment were measured.

During the implementation the following works were carried out: validation of the technique for reconstructing sea wave spectra from the ones of highresolution satellite images, validation of the selection results of aquatic environment optical anomalies from satellite images due to the entry of deep drains into the coastal waters from emergency breaks of dumping device collectors. Based on the processing of the obtained experimental data, the level of anthropogenic impacts on the coastal waters was quantified for a number of test polygons. The emergency state of deep wastewater collectors has been identified. An extensive database of ground and space data has been compiled. The effectiveness of integrated ground-to-space monitoring for identifying anthropogenic impacts on coastal waters was demonstrated.

\section{REFERENCES}

1. Zaitsev, Yu., 2008. Introduction to the Black Sea Ecology. Odessa: Smil Edition and Publishing Agency ltd, 228 p. Available at: http://hdl.handle.net/1834/12945 [Accessed: 20 December 2020].

2. Bondur, V.G., Vorobyev, V.E., Zamshin, V.V., Serebryany, A.N., Latushkin, A.A., Li, M.E., Martynov, O.V., Hurchak, A.P. and Grinchenko, D.V., 2018. Monitoring Anthropogenic Impact on Some Coastal Water Areas of the Black Sea Using Multispectral Satellite Imagery. Izvestiya, Atmospheric and Oceanic Physics, 54(9), pp. 1008-1022. https://doi.org/10.1134/S0001433818090098

3. Oguz, T. and Velikova, V., 2010. Abrupt Transition of the Northwestern Black Sea Shelf Ecosystem from a Eutrophic to an Alternative Pristine State. Marine Ecology Progress Series, 405, pp. 231-242. https://doi.org/10.3354/meps08538

4. Borja, A., 2014. Grand Challenges in Marine Ecosystems Ecology. Frontiers in Marine Science, 1, 1. https://doi.org/10.3389/fmars.2014.00001

5. Acocella, V., 2015. Grand Challenges in Earth Science: Research Toward a Sustainable Environment. Frontiers in Earth Science, 3, 68. https://doi.org/10.3389/feart.2015.00068

6. Muller-Karger, F.E., Hestir, E., Ade, C., Turpie, K., Roberts, D.A., Siegel, D., Miller, R.J., Humm, D. and Izenberg, N. [et al.], 2018. Satellite Sensor Requirements for Monitoring Essential Biodiversity Variables of Coastal Ecosystems. Ecological Applications, 28, pp. 749760. https://doi.org/10.1002/eap.1682 
7. Ghosh, M.K., Kumar, L. and Roy, C., 2015. Monitoring the Coastline Change of Hatiya Island in Bangladesh Using Remote Sensing Techniques. ISPRS Journal of Photogrammetry and Remote Sensing, 101, pp. 137-144. https://doi.org/10.1016/j.isprsjprs.2014.12.009

8. Ivanov, V.A. and Dulov, V.A., eds., 2014. Monitoring of the Coastal Zone in the Black Sea Experimental Sub-Satellite Testing Area. Sevastopol: ECOSI-Gidrofizika, 526 p. (in Russian).

9. Bondur, V.G., Filatov, N.N., Grebenyuk, Y.V., Dolotov, Yu.S., Zdorovennov, R.E., Petrov, M.P. and Tsidilina, M.N., 2007. Studies of Hydrophysical Processes During Monitoring of the Anthropogenic Impact on Coastal Basins Using the Example of Mamala Bay of Oahu Island in Hawaii. Oceanology, 47(6), pp. 769-787. https://doi.org/10.1134/S0001437007060033

10. Bondur, V. and Tsidilina, M., 2005. Features of Formation of Remote Sensing and Sea Truth Databases for the Monitoring of Anthropogenic Impact on Ecosystems of Coastal Water Areas. In: ISRSE, 2005. Proceedings of 31st International Symposium on Remote Sensing of Environment. ISRSE, pp. 192-195.

11. Keeler, R., Bondur, V.G. and Vithanage, D., 2004. Sea Truth Measurements for Remote Sensing of Littoral Water. Sea Technology, 45(4), pp. 53-58.

12. Bondur, V.G., Keeler, R.N., Starchenkov, S.A. and Rybakova, N.I., 2006. Monitoring of the Pollution of the Ocean Coastal Water Areas Using Space Multispectral High Resolution Imagery. Issledovanie Zemli iz Kosmosa, (6), pp. 42-49 (in Russian).

13. Bondur, V.G. and Zubkov, E.V., 2005. Showing up the Small-Scale Ocean Upper Layer Optical Inhomogeneities by the Multispectral Space Images with the High Surface Resolution. Part 1. The Canals and Channels Drainage Effects at the Coastal Zone. Issledovanie Zemli iz Kosmosa, (4), pp. 54-61 (in Russian).

14. Bondur, V., 2005. Complex Satellite Monitoring of Coastal Water Areas. In: ISRSE, 2005. Proceedings of 31st International Symposium on Remote Sensing of Environment. ISRSE, 7 p. Available at: http://www.aerocosmos.info/pdf/1/2005_31_ISRSE_Bondur.pdf [Accessed: 10 December 2019].

15. Bondur, V.G., 2011. Satellite Monitoring and Mathematical Modelling of Deep Runoff Turbulent Jets in Coastal Water Areas. In: F.S. García Einschlag ed., 2011. Waste Water Evaluation and Management. London: Intech OpenLimited, pp. 155-180. doi:10.5772/16134

16. Lavrova, O.Yu., Kostianoy, A.G., Lebedev, S.A., Mityagina, V.I., Ginzburg, A.I., Sheremet, N.A., 2011. Complex Satellite Monitoring of the Russian Seas. Moscow: SRI RAS, 470 p. (in Russian).

17. Robinson, I.S., 2010. Discovering the Ocean from Space. The Unique Applications of Satellite Oceanography. Berlin: Springer, 638 p. doi:10.1007/978-3-540-68322-3

18. Lavrova, O.Yu., Mityagina, M.I. and Kostianoy, A.G., 2016. Satellite Methods for Detecting and Monitoring Marine Zones of Ecological Risk. Moscow: SRI RAS, 336 p.

19. Bruno, M.F., Molfetta, M.G., Pratola, L., Mossa, M., Nutricato, R., Morea, A., Nitti, D.O. and Chiaradia, M.T., 2019. A Combined Approach of Field Data and Earth Observation for Coastal Risk Assessment. Sensors, 19(6), 1399. https://doi.org/10.3390/s19061399

20. Bondur, V.G. and Starchenkov, S.A., 2001. [Methods and Programs of Aerospace Imagery Processing and Classification]. Proceedings of the Higher Educational Institutions. Izvestia Vuzov «Geodesy and Aerophotosurveying», (3), pp. 118-143 (in Russian).

21. Bondur, V.G., Zhurbas, V.M. and Grebenyuk, Y.V., 2006. Mathematical Modeling of Turbulent Jets of Deep-Water Sewage Discharge into Coastal Basins. Oceanology, 46(6), pp. 757-771. https://doi.org/10.1134/S0001437006060014

22. Bondur, V.G., Grebenjuk, Y.V. and Sabinin, K.D., 2008. Variability of Internal Tides in the Coastal Water Area of Oahu Island (Hawaii). Oceanology, 48(5), pp.611-621. https://doi.org/10.1134/S0001437008050019

23. Bondur, V.G., Grebenyuk, Y.V. and Sabynin, K.D., 2009. The Spectral Characteristics and Kinematics of Short-Period Internal Waves on the Hawaiian Shelf. Izvestiya, Atmospheric and Oceanic Physics, 45(5), 598. https://doi.org/10.1134/S0001433809050077 
24. Bondur, V.G. and Zamshin, V.V., 2018. Comprehensive Ground-Space Monitoring of Anthropogenic Impact on Russian Black Sea Coastal Water Areas. In: K. Anisimov [et al.], eds., 2018. Proceedings of the Scientific-Practical Conference "Research and Development2016”. Cham: Springer, pp. 625-637. https://doi.org/10.1007/978-3-319-62870-7_66

25. Bondur, V.G., Dulov, V.A., Murynin, A.B. and Ignatiev, V.Yu., 2016. Retrieving Sea-Wave Spectra Using Satellite-Imagery Spectra in a Wide Range of Frequencies. Izvestiya, Atmospheric and Oceanic Physics, 52(6), pp. 637-648. https://doi.org/10.1134/S0001433816060049

26. Bondur, V.G., Ivanov, V.A., Dulov, V.A., Goryachkin, Yu.N., Zamshin, V.V., Kondratiev, S.I., Lee, M.E., Mukhanov, V.S., Sovga, E.E. and Chukharev, A.M., 2018. Structure and Origin of the Underwater Plume Near Sevastopol. Fundamentalnaya $i$ Prikladnaya Gidrofizika, 11(4), pp. 42-54. doi:10.7868/S2073667318040068

27. Dolotov, V.V. and Dolotov, A.V., 2016. GIS for Monitoring of Anthropogenic Pressure to the Sea Shelf Zones. In: SSC RAS, 2016. Indicators of Climatic Changes in Marine Ecosystems: Collection of articles of the IV International Conference GeoiD'2016 (October 3-7, 2016, Sukhum, Abkhazia). Rostov-on-Don: SSC RAS Publishers, pp. 16-27. Available at: https://www.researchgate.net/publication/312470190_GIS_for_monitoring_of_anthropogenic_p ressure_to_the_sea_shelf_zones [Accessed: 10 December 2019].

28. Dulov, B.A., Yurovskaya, M.V. and Kozlov, I.E., 2015. Coastal Zone of Sevastopol on High Resolution Satellite Images. Physical Oceanography, (6), pp. 39-54. doi:10.22449/1573160X-2015-6-39-54

About the authors:

Valeriy G. Bondur - Scientific Director, AEROCOSMOS Research Institute for Aerospace Monitoring (4 Gorokhovskiy per., Moscow, 105064, Russian Federation), Dr. Sci. (Engineering), Professor, Vice President of Russian Academy of Sciences, ORCID ID: 0000-0002-2049-6176, ResearcherID: G-3130-2014, SPIN-code: 3671-9808, Scopus Author ID: 6602420154, vgbondur@aerocosmos.info

Vitaliy A. Ivanov, Head of Research Group on Coastal Studies, Marine Hydrophysical Institute of RAS (2 Kapitanskaya Str., Sevastopol, 299011, Russian Federation), Academician of Russian Academy of Sciences, Dr. Sci. (Phys.-Math.), Professor, ResearcherID: I-7436-2013

Vladimir E. Vorob'ev, Interim Director, AEROCOSMOS Research Institute for Aerospace Monitoring (4 Gorokhovskiy per., Moscow, 105064, Russian Federation), ORCID ID: 0000-00030834-496X, ResearcherID: G-3172-2014, SPIN-code: 4803-5315, Scopus Author ID: 57200694592, office@aerocosmos.info

Vladimir A. Dulov, Head of Applied Sea Physics Laboratory of Remote Sensing Department, Marine Hydrophysical Institute of RAS (2 Kapitanskaya Str., Sevastopol, 299011, Russian Federation), Dr. Sci. (Phys.-Math.), ORCID ID: 0000-0002-0038-7255, ResearcherID: F-8868-2014, SPIN-code: 8303-6244, Scopus Author ID: 6602725409, dulov@mhi-ras.ru

Vyacheslav V. Dolotov, Senior Research Associate, Marine Hydrophysical Institute of RAS (2 Kapitanskaya Str., Sevastopol, 299011, Russian Federation), Ph. D. (Chem.), ORCID ID: 0000-0002-1485-2883, ResearcherID: N-3047-2017, SPIN-code: 1496-5526, Scopus Author ID: 6602997067, vdolotov@mail.ru

Victor V. Zamshin, Head of the Aerospace Information Processing Department, AEROCOSMOS Research Institute for Aerospace Monitoring (4 Gorokhovskiy per., Moscow, 105064, Russian Federation), ORCID ID: 0000-0003-4285-172X, ResearcherID: G-3224-2014, SPIN-code: 1416-0616, Scopus Author ID: 57205502046, office@ aerocosmos.info

Sergey I. Kondratev, Senior Research Associate, Marine Hydrophysical Institute of RAS (2 Kapitanskaya Str., Sevastopol, 299011, Russian Federation), Ph. D. (Chem.), ORCID ID: 0000-0002-2049-7750, ResearcherID: F-8972-2019, SPIN-код: 1496-5526, Scopus Author ID: 35784380700, skondratt@mail.ru 
Michael E. Lee, Chief Research Associate, Head of Marine Optics and Biophysics Department, Marine Hydrophysical Institute of RAS (2 Kapitanskaya Str., Sevastopol, 299011, Russian Federation), Dr. Sci. (Phys.-Math.), Professor, ORCID ID: 0000-0002-2292-1877, ResearcherID: R-4344-2018, SPIN-code: 2479-6915, Scopus Author ID: 56142710400, michael.lee.mhi@gmail.com

Vladimir V. Malinovsky, Senior Research Associate, Marine Hydrophysical Institute of RAS (2 Kapitanskaya Str., Sevastopol, 299011, Russian Federation), Ph. D. (Phys.-Math.), ORCID ID: 0000-0002-5799-454X, ResearcherID: F-8709-2014, SPIN-code: 9206-3020, Scopus Author ID: 23012976200, vladimir.malinovsky@mhi-ras.ru

Contribution of the co-authors:

Valery G. Bondur - development and scientific substantiation of the research concept, general scientific research management, formulation of conclusions, paper editing

Vitaly A. Ivanov - statement of goals and research organization, work management, analysis of results and formulation of conclusions

Vladimir E. Vorob'ev - collection, processing and analysis of remote sensing data

Vladimir A. Dulov - participation in the work organization, collection of wave recording information, analysis of experimental data, preparation of the paper text

Vyacheslav V. Dolotov - development of the operator's workplace, including GIS, access to a ground-based monitoring database, data visualization.

Viktor V. Zamshin - collection, processing and analysis of remote sensing data, generalization of the obtained data using geographic information technologies

Sergey I. Kondratev - participation in the organization of shipwork, measurement and collection of hydrochemical characteristics, analysis of their fields and formulation of conclusions.

Michael E. Lee - collection, processing and analysis of data on the optical characteristics of coastal plumes during experiments on a research vessel

Vladimir V. Malinovsky - participation in the organization of expeditions on a research vessel and oceanographic platform, collection and analysis of meteorological information

All the authors have read and approved the final manuscript.

The authors declare that they have no conflict of interest. 